\title{
A rare cause of acute mechanical intestinal obstruction: a strangulated obturator hernia
}

\author{
Dogan Erdogan, Mehmet Gulmez, V. Melih Kara, Mehmet Ali Uzun, Osman Yucel \\ Department of General Surgery, Haydarpasa Numune Training and Research Hospital, Istanbul, Turkey
}

\begin{abstract}
Obturator hernia is a rarely-seen type of abdominopelvic hernia. It is generally seen in thinner, old, multipara patients. The most frequently seen clinical sign is intestinal obstruction associated with strangulation. Diagnosis is generally made during operation in patients brought into emergency room because of intestinal obstruction. Delay in diagnosis in older patients results in higher rates of morbidity and mortality. Herein, we present a 68-year-old multipara patient who consulted to the emergency service with clinical manifestations of intestinal obstruction, and who was operated with the preoperative diagnosis of "strangulated obturator hernia" established by means of computed-tomography.
\end{abstract}

Key words: Intestinal obstruction; obturator hernia strangulation.

$\mathrm{O}$ bturator hernia is a rare type of hernia, seen in $0.4 \%$ of patients who present with clinical manifestations of intestinal obstruction, and constituting $0.07 \%$ of all abdominopelvic hernias [1]. It is generally seen in old and thin multipara patients. It is encountered 9 times more frequently in women because of their wider intrapelvic obturator channel [2]. Most frequently, strangulation is associated with intestinal obstruction. Diagnosis is generally made during emergency operation performed with the indication of intestinal obstruction. Because of its frequent occurrence in older patients, and delayed recognition due to difficulties encountered during the diagnostic process, it causes higher rates of mortality and morbidity. We present a patient who was referred to the emergency service with clinical manifestations of intestinal obstruction, and operated urgently with the diagnosis of strangulated obturator hernia based on computed tomographic findings.

\section{CASE REPORT}

A 68-year-old female patient presented to our emergency service with inability to pass gas and feces for 2 days, abdominal distension, and vomiting. Her personal medical history was unremarkable, without any previous disease or operation. This multipara patient was $155 \mathrm{~cm}$ tall, and weighed $40 \mathrm{~kg}$. Her vital signs were as follows: ABP $120 / 70 \mathrm{mmHg}$,

Received: June 30, 2014 Accepted: November 18, 2014 Online: April 24, 2015

Correspondence: Dr. Mehmet GULMEZ. Haydarpasa Numune Egitim ve Arastirma Hastanesi, Genel Cerrahi Klinigi, Tibbiye Caddesi, 34668 Uskudar, Istanbul, Turkey. 
pulse rate: $78 / \mathrm{min}$, respiratory rate: $23 / \mathrm{min}$, body temperature: $36.7^{\circ} \mathrm{C}$. Physical examination revealed abdominal distension without abdominal guarding, and rebound tenderness. The rectal ampulla was empty on digital rectal examination. Other system examinations were unremarkable. Results of laboratory tests were as follows: Htc: $43.1 \%$; WBC: $11700 / \mathrm{mm}^{3}$, glucose: $125 \mathrm{mg} / \mathrm{dL}, \mathrm{BUN}: 61 \mathrm{mg} / \mathrm{dL}$, creatinine: $1.21 \mathrm{mg} / \mathrm{dL}$, sodium: $135 \mathrm{mEq} / \mathrm{L}$, potassium: $4.3 \mathrm{mEq} / \mathrm{L}$. Standing KUB revealed air-fluid level of intestines (Figure 1). On whole abdominal ultrasound, dilated intestinal loops, and free fluid between intestinal loops were detected. Computed tomography (CT) demonstrated obstructive obturator hernia on the left side (Figures 2a, b). The patient was operated urgently with the diagnosis of intestinal obstruction caused by strangulated obturator hernia. On exploration, a strangulated intestinal loop was detected within the left obturator channel, and reduced. Intestinal ischemia, necrosis or perforation were not detected, so additional intervention was not performed. The defect was repaired using a polypropylene mesh placed in the preperitoneal region. The patient was lost on postoperative 3rd day because of acute respiratory failure.

\section{DISCUSSION}

Obturator hernia is a type of pelvic hernia developed as a result of herniation of the obturator nerve and muscles from the obturator foramen, and is a rarely seen surgical pathology. Obturator hernia is called the "hernia of the small old woman", because it is generally seen in thin, multipara women of advanced age. Since the intrapelvic obturator channel

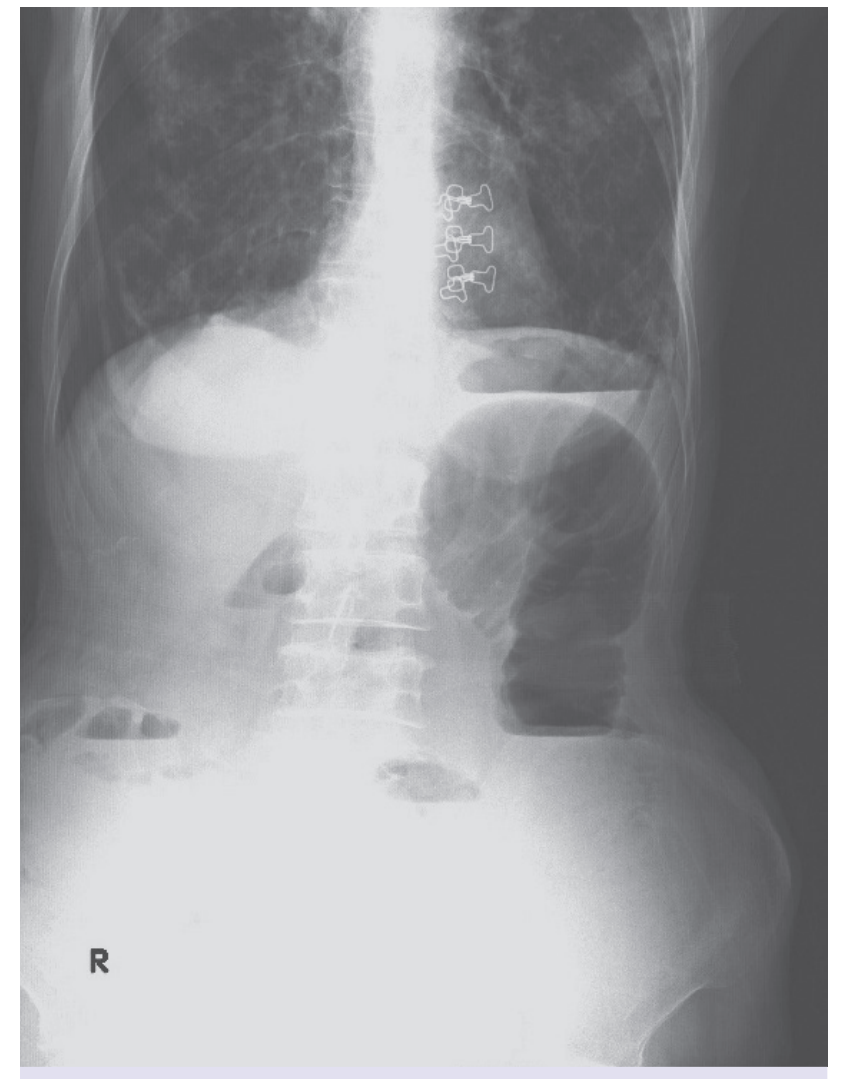

FIGURE 1. Standing abdominal radiograph showing dilated intestinal loop, and air-fluid level.

is wider in women, it is seen 9 times more frequently in women [2]. Conditions which increase intra-abdominal pressure predispose to the development of obturator hernia. In compliance with the literature findings, our case was an old, and thin multipara patient. She had a left-sided hernia, and had not been operated previously.
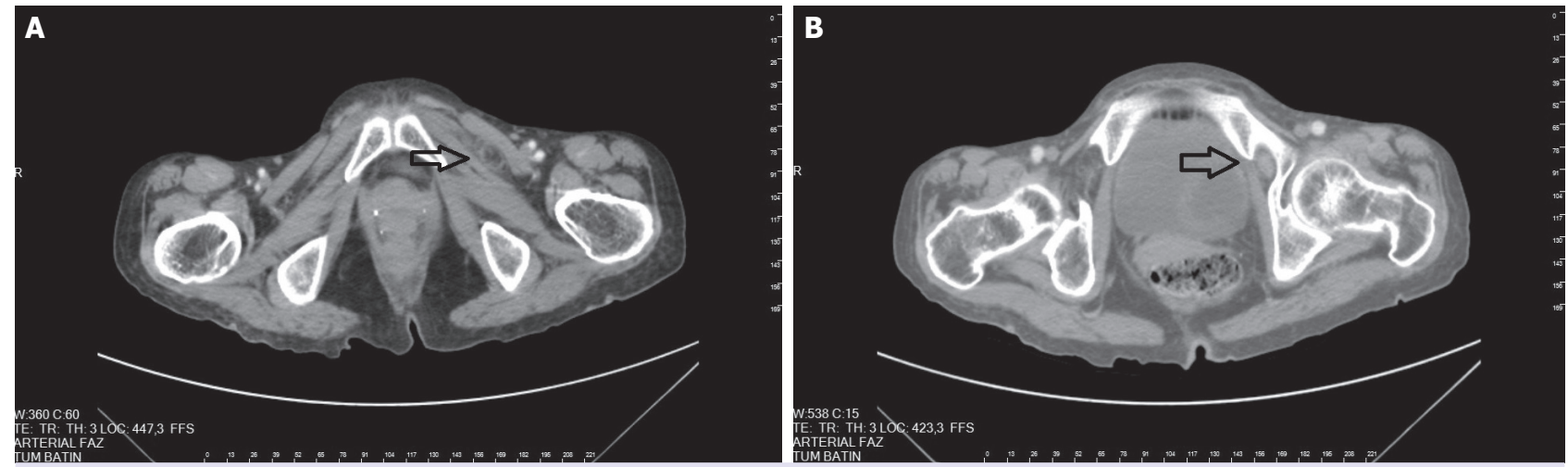

FIGURE2. Intestinal loop in the left inguinal obturator channel. 
The clinical findings of obturator hernia are generally not specific. Occasionally, its diagnosis is delayed until diagnostic laparotomy is performed. The most frequently seen $(80 \%)$ clinical picture is intestinal obstruction. Usually, acute obstruction is seen in association with strangulation. The most frequently detected second manifestation is the Howship-Romberg sign. This occurs when the anterior branch of the obturator nerve is impinged by hernial sac content, which causes pain at medial aspect of the femur and sometimes knee. It is seen in $15-50 \%$ of obturator hernia cases [3]. Other signs of a strangulated obturator hernia include ecchymosis seen on the internal aspect of the femur, and below the inguinal ligament, and a laterally situated tender obturator mass palpated during vaginal examination. If the hernial sac descends below the pectineus muscle, it can be palpated as an inguinal mass. This mass is best palpated when the femur is brought into flexion, adduction, and outer rotation [4]. Another manifestation of an obturator hernia is the HanningtonKiff sign. This signifies preservation of patellar reflex, and simultaneous loss of adductor reflex of the patella. In detection of an obturator hernia, it is more specific compared to the Howship-Romberg sign. Our patient consulted to our emergency service with clinical manifestations of intestinal obstruction identified during vaginal examination.

Patients cannot be diagnosed without development of obstruction. Hip and leg pains are evaluated as neuromuscular pain, and assessed in the departments of neurology, orthopedics, neurosurgery or gynecology and obstetrics, which consequently delays diagnosis. If patients with hip and leg pains carry risk factors for obturator hernia, even in the absence of clinical manifestations of intestinal obstruction, before making a diagnosis of neuromuscular pain, potential diagnosis of obturator hernia should be kept in mind.

In patients who present with abdominal pain suggesting intestinal obstruction, abdominal CT should be done for differential diagnosis [2]. In strangulated obturator hernia with high mortality rates, preoperative diagnosis can rarely be made. Although ultrasound (US) is a rapid, noninvasive, cost-effective, and easily-available diagnostic method, it is difficult to arrive at a diagnosis of obturator hernia using US. Diagnostic accuracy of preopera- tive abdominal CT has been reported as $90 \%$ in cases with obturator hernia $[5,6]$. In our patient, preoperative diagnosis of obturator hernia was made using abdominal CT, and the patient was operated with this indication.

In the management of intestinal obstruction, emergency surgery is most frequently preferred [4]. Various types of surgical interventions have been described. If left unrepaired, recurrence rates climb to 10 percent [4]. The defect of the obturator channel or contaminated perforation can be closed primarily or repaired using polypropylene mesh [7]. Because of suspicion of strangulation, we preferred the abdominal approach, and repaired the defect with preperitoneal polypropylene mesh.

\section{Conclusion}

Obturator hernia is a rare cause of intestinal obstruction. However, because of its higher mortality rates in case of delay in diagnosis and treatment in older, multipara, thin patients who have not previously undergone abdominal operation, and who present to the emergency service with a clinical picture of intestinal obstruction, obturator hernia should be suspected, and contrast-enhanced abdominal CT should be requested for early diagnosis and treatment.

Conflict of Interest: No conflict of interest was declared by the authors.

Financial Disclosure: The authors declared that this study has received no financial support.

\section{REFERENCES}

1. Yokoyama Y, Yamaguchi A, Isogai M, Hori A, Kaneoka Y. Thirty-six cases of obturator hernia: does computed tomography contribute to postoperative outcome? World J Surg 1999;23:214-7.

2. Chang SS, Shan YS, Lin YJ, Tai YS, Lin PW. A review of obturator hernia and a proposed algorithm for its diagnosis and treatment. World J Surg 2005;29:450-4. CrossRef

3. Mantoo SK, Mak K, Tan TJ. Obturator hernia: diagnosis and treatment in the modern era. Singapore Med J 2009;50:866-70.

4. Mandarry MT, Zeng SB, Wei ZQ, Zhang C, Wang ZW. Obturator hernia--a condition seldom thought of and hence seldom sought. Int J Colorectal Dis 2012;27:133-41. CrossRef

5. Wang GY, Qian HR, Cai XY, Fang SH, Shen LG. Strangulated obturator hernia diagnosed preoperatively by spiral CT: case report. Chin Med J (Engl) 2007;120:1855-6. 
6. Agar NJ, Mooney BM, Nagorcka J. Obturator hernia case report: early diagnosis with the help of computed tomography. ANZ J Surg 2008;78:508. CrossRef
7. Agarwal D, Sharma G, Agarwal NN, Rao J, Garg KM. Interstinal obstruction due to obturator hernia \{a rarest presentation\}. Indian J Surg 2013;75(Suppl 1):388-90. CrossRef 